\title{
A Milestone of Acta Polytechnica Hungarica
}

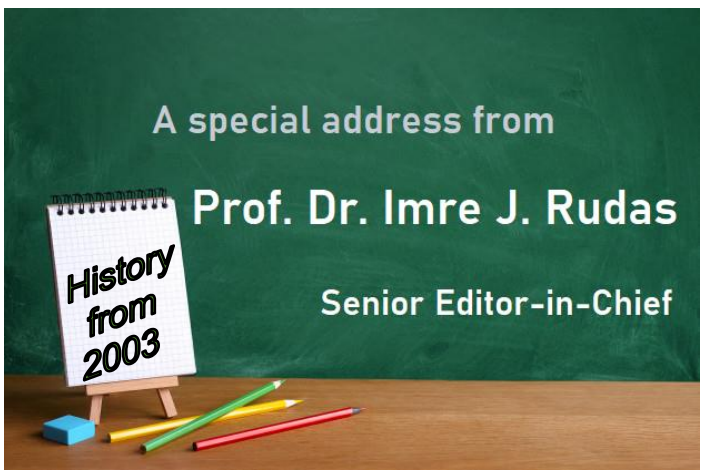

Acta Polytechica Hungarica is a part of my heart, I am proud of it like a father being proud of his child. My first thought, when I am addressing the readers at last with this special issue is that 17 years passed like a single day.

The journal history started in 2003. I was elected as the Rector of Budapest Tech, the successor of three Polytechnic types Colleges namely, Bánki Donát Polytechnic, Kandó Kálmán Technical College and College of Light Industry. I prepared a new institutional strategic plan, where one of the main goals was to establish an international scientific Journal in order to provide a publication platform for our scholars and citizens.

I invited Prof. Dr. András Bakó to be the first Editor-in-Chief, and established the International Editorial Board constituting of highly recognized scientist. Since the beginning till 2014, I was the Chair of the Editorial Board and Honorary Editor-inChief. After some discussions with the Board members, I decided to give the name, mission and scope to the new Journal

\section{Acta Polytechnica Hungarica \\ Journal of Applied Sciences}

\section{Mission Statement}

Acta Polytechnica Hungarica should be an internationally highly recognized, professionally operated Scientific Journal with high Impact Factor.

\section{Aims and Scope}

Acta Polytechnica Hungarica is a multidisciplinary international peer reviewed journal of applied sciences publishing high-quality articles in over 6 issues per year. The journal aims to provide an international forum for the publication of original, fundamental research and applications-based results in engineering sciences as follows: 
- Mechanical Engineering

- Electrical Engineering

- Informatics and a

- Special Track for Selected topics in Engineering only for invited papers.

Manuscripts with high standards of scientific quality are only published in the Journal. This is ensured by subjecting each paper to a strict assessment procedure by members of the Editorial Board and the International Advisory Board. The objective is to establish that papers submitted do meet our established requirements. The review is based on the justification of these technical and quality criteria (see Editorial Policy).

After a few early successful years, IEEE Hungary Section joined as a cosponsor of Acta Polytechnica Hungarica, and since that time, has had a great contribution to success.

It took five years to the new Journal to reach an international recognition; in 2008 it was selected for coverage in Thomson Reuters products and custom information services. Beginning with V. 5 (1) 2008, this publication was indexed and abstracted in the following:

- Science Citation Index Expanded (also known as SciSearch®)

- Journal Citation Reports/Science Edition.

Let me recall here a part of our Editorial Policy:

Acta Polytechnica Hungarica has been accepted for coverage in selected Elsevier product(s) starting with 2009 material. Elsevier intends to index and extract data from the full text article and integrate such data in these product(s). Coverage in Elsevier products increases dissemination of authors' work via linking technologies, which drive additional traffic to individual articles, promoting journal brand awareness. The benefits are high visibility to a global audience, fast online dissemination of content and increased exposure and profile for authors and editors.

In 2010 Acta Polytechnica Hungarica was added to Directory of Open Access Journals (DOAJ) which provides many benefits:

- Journals with the content in PDF format will be included in long term preservation project.

- Statistics show more than 6 millions successful requests a month for DOAJ site from all over the world.

- Many web crawlers are fetching the content of DOAJ to be a part of their search engines.

- DOAJ is OAI compliant. 
- Once the article is available in DOAJ, it becomes automatically OAI harvestable.

- Many aggregators and database providers are regularly harvesting DOAJ content in order to include it to their commercial databases.

It is cited here to give an example of the long journey and continuous progress Acta Polytechnica Hungarica has made. All that leads to increased visibility and usage of OA journals. The Journal received the Impact Factor first in 2010. The 2019 Impact Factor is 1.219.

The trend of Impact Factor can be seen in figure below.

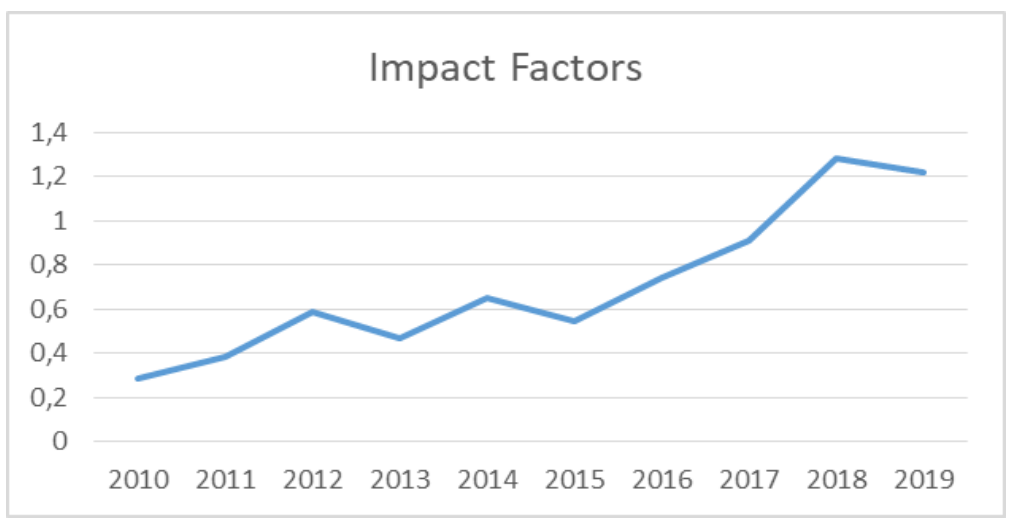

After Prof. Bakó's term, the Editor-in-Chiefs were Profs. János Fodor and Péter Tóth. I thank them all for their efforts devoted to our Journal. I took over the position in 2014.

Since the beginning, the Executive Editor has been Anikó Szakál. Without her contribution of great value, these results would not have been achieved.

After 17 years, I am now ready to step down as the senior Editor-in-Chief. I wish the incoming Editor-in-Chief, Prof. Levente Kovács a good momentum and inspiration to further improve the standard of the Journal and strengthen its international recognition.

My "child" has grown up, it needs fresh blood and should be open to new challenges. As the founding father, I wish further successes and I hope I can always remain proud of Acta Polytechnica Hungarica.

Prof. Dr. Imre J. Rudas

Senior Editor-in-Chief

Budapest, April 6, 2021

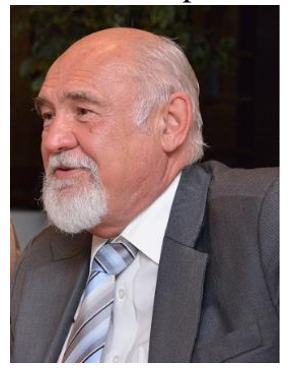

